\title{
How oxygen makes its presence felt
}

\author{
William G. Kaelin, Jr. ${ }^{1}$
}

Howard Hughes Medical Institute, Dana-Farber Cancer Institute, and Brigham and Womens Hospital, Harvard Medical School, Boston, Massachusetts 02115, USA

The emergence of complex multicellular organisms during evolution required systems for ensuring adequate cellular oxygenation. Any reader doubting the veracity of this statement is invited to hold his or her breath while reading the remainder of this article. For this reason, considerable effort has been devoted to understanding how cells in higher eukaryotes sense and respond to changes in oxygen availability. Over the years a number of models were put forth to explain how cells sense oxygen. Unfortunately, these models were complex and, at times, contradictory. For example, some models suggested that a decrease in intracellular reactive oxygen species (ROS) gave rise to a low oxygen (hypoxia) signal whereas other models suggested the opposite (Semenza 1999). Likewise, some models suggested that mitochondria were categorically required for delivery of a hypoxic signal whereas others did not (Chandel et al. 1998; Srinivas et al. 2001; Vaux et al. 2001). Approximately one year ago, however, a surprisingly simple and conceptually attractive picture of oxygen sensing began to emerge. At the heart of this model is a posttranslational modification, hydroxylation, that is inherently oxygen-dependent, and a transcription factor called HIF (hypoxia-inducible factor).

It has been known for some time that HIF is a master regulator of genes that are activated by low oxygen levels (Semenza 2001). These genes encode proteins that play roles in the acute and chronic adaptation to oxygen deficiency. The former include proteins involved in regulating glucose uptake, glucose metabolism, and extracellular $\mathrm{pH}$, which allow for continued energy generation in a hypoxic environment. The latter include proteins involved in angiogenesis and erythropoiesis, which increase blood vessel density and blood oxygen-carrying capacity, respectively. HIF is a heterodimer consisting of one of three alpha subunits (HIF- $1 \alpha$, HIF- $2 \alpha$, or HIF- $3 \alpha$ ) and a beta subunit (HIF-1 $\beta$, also called Aryl Hydrocarbon Nuclear Translocator, or ARNT). As its name suggests, HIF is only active under hypoxic conditions. This is because the alpha subunits are rapidly degraded in the presence of oxygen due to polyubiquitination by an E3 ubiquitin ligase complex that contains the von HippelLindau tumor suppressor protein $(\mathrm{pVHL})$, elongin $\mathrm{B}$, elongin $\mathrm{C}, \mathrm{Cul} 2$, and Rbx1 (also called ROC1 or Hrt1)

${ }^{1}$ E-MAIL william_kaelin@dfci.harvard.edu; FAX (617) 632-4760. Article and publication are at http://www.genesdev.org/cgi/doi/10.1101/ gad.1003602.
(Semenza 2001; Yang and Kaelin 2001). The best studied of the alpha subunits is the ubiquitous HIF- $1 \alpha$. pVHL binds directly to a peptidic determinant located within a region of HIF- $1 \alpha$ called the oxygen-dependent degradation domain (ODD), which overlaps with the HIF- $1 \alpha \mathrm{N}$ terminal transactivation domain (NTAD) and is sufficient to render heterologous proteins unstable in the presence of oxygen.

\section{Control of HIF stability by prolyl hydroxylation}

Last year three groups showed that the interaction of pVHL with the ODD is governed by hydroxylation of a highly conserved prolyl residue within the HIF NTAD (Ivan et al. 2001; Jaakkola et al. 2001; Yu et al. 2001). This hydroxylated prolyl residue forms two critical hydrogen bonds with pVHL side chains present within the beta domain, which constitutes the pVHL substrate recognition unit (Min et al. 2002). A second prolyl hydroxylation site near the NTAD that can also be recognized by pVHL has also been identified (Masson et al. 2001). In mammalian cells, HIF prolyl hydroxylation is carried out by one of three orthologs of C. elegans Egl-9 (called EGLN1, EGLN2, and EGLN3; also called PHD2, PHD1, and PHD3, respectively, or HPH-2, HPH-3, and HPH-1, respectively) (Bruick and McKnight 2001b; Epstein et al. 2001; Taylor 2001; Ivan et al. 2002). For simplicity, Egl-9 will be used when referring to these orthologs generically. This enzymatic reaction is inherently oxygen-dependent as the oxygen atom of the hydroxy group is derived from molecular oxygen. Moreover, the rate of hydroxylation by recombinant Egl-9 varies with changes in ambient oxygen over a physiologically relevant range (Epstein et al. 2001). In addition, prolyl hydroxylation requires 2-oxoglutarate and iron as cofactors, thereby accounting for the well known 'hypoxia-mimetic' effects of iron antagonists such as desferrioxamine and cobalt chloride (Kivirikko and Myllyharju 1998; Schofield and Zhang 1999). 2-oxoglutarate is required because the hydroxylation reaction is coupled to decarboxylation of 2-oxoglutarate to succinate, which accepts the remaining oxygen atom (Kivirikko and Myllyharju 1998). In summary, the mammalian oxygen-sensing pathway involves the oxygen-dependent prolyl hydroxylation of HIF by Egl-9, which then serves as a signal for pVHL-dependent polyubiqutination and proteasomal degradation. This pathway is conserved in C. elegans and Drosophila (Bruick and McKnight 2001b; Epstein et al. 2001). 


\section{Asparaginyl hydroxylation and HIF transactivation function}

It would not be surprising if HIF were regulated at multiple levels given its pivotal role in sensing and responding to changes in oxygen. Indeed, it has been reported that oxygen affects the subcellular localization, DNAbinding capability, and transcriptional activation function of HIF- $1 \alpha$ in addition to regulating its stability. A clear example of this relates to the behavior of the HIF-1 $\alpha$ C-terminal transactivation domain (CTAD) which, when fused to a heterologous DNA-binding domain, is constitutively stable and yet only activates transcription under hypoxic conditions. A recent report showed that this phenomenon is due to hydroxylation of a critical asparagine residue within the CTAD, which in turn renders CTAD unable to bind to the p300/CBP coactivators (Lando et al. 2002b). Under hypoxic conditions, or following treatment with iron chelators or 2-oxoglutarate antagonists, this hydroxylation does not take place and coactivator recruitment can occur (Lando et al. 2002b; Sang et al. 2002). The structures of the HIF$1 \alpha$ CTAD bound to either the p300 or CBP CH1 domains have been solved (Dames et al. 2002; Freedman et al. 2002). They reveal that the CTAD is induced to form a vice-like clamp around the $\mathrm{CH} 1$ domain, which can be viewed as acting like a scaffold. The hydroxylatable CTAD asparagine is located within an alpha helix that is buried in a hydrophobic pocket formed by $\mathrm{CH} 1$ (Dames et al. 2002; Freedman et al. 2002). This interaction would be disrupted following asparagine hydroxylation.

In this issue of Genes \& Development, Lando and coworkers (2002a) mined databases looking for proteins that might represent novel protein hydroxylases (Lando et al. 2002a). Similar in silico approaches by others, coupled with genetic manipulations in model organisms, led earlier to the identification of the HIF prolyl hydroxylases (Aravind and Koonin 2001; Bruick and McKnight 2001b; Epstein et al. 2001). Lando and coworkers determined that FIH-1, which was initially identified by Semenza and coworkers as an HIF-binding protein and shown to repress CTAD function (Mahon et al. 2001), had the features of a 2-oxoglutarate-dependent protein hydroxylase. They went on to show that recombinant FIH-1 hydroxylates the above mentioned asparagine residue within the HIF CTAD. Moreover, they showed that FIH-1 variants in which highly conserved residues within the predicted catalytic domain were altered could no longer repress HIF CTAD function. Thus, inhibition of HIF CTAD function by FIH-1-dependent asparaginyl hydroxylation appears to add another level to the control of HIF by oxygen (Fig. 1). Gene disruption studies will be required to determine if there are additional proteins that can also act as HIF asparaginyl hydroxylases. The importance of CTAD hydroxylation is challenged, however, by the observation that hypoxia and hypoxia-mimetics do not markedly enhance hypoxia-inducible gene expression in pVHL-defective cells (Iliopoulos et al.

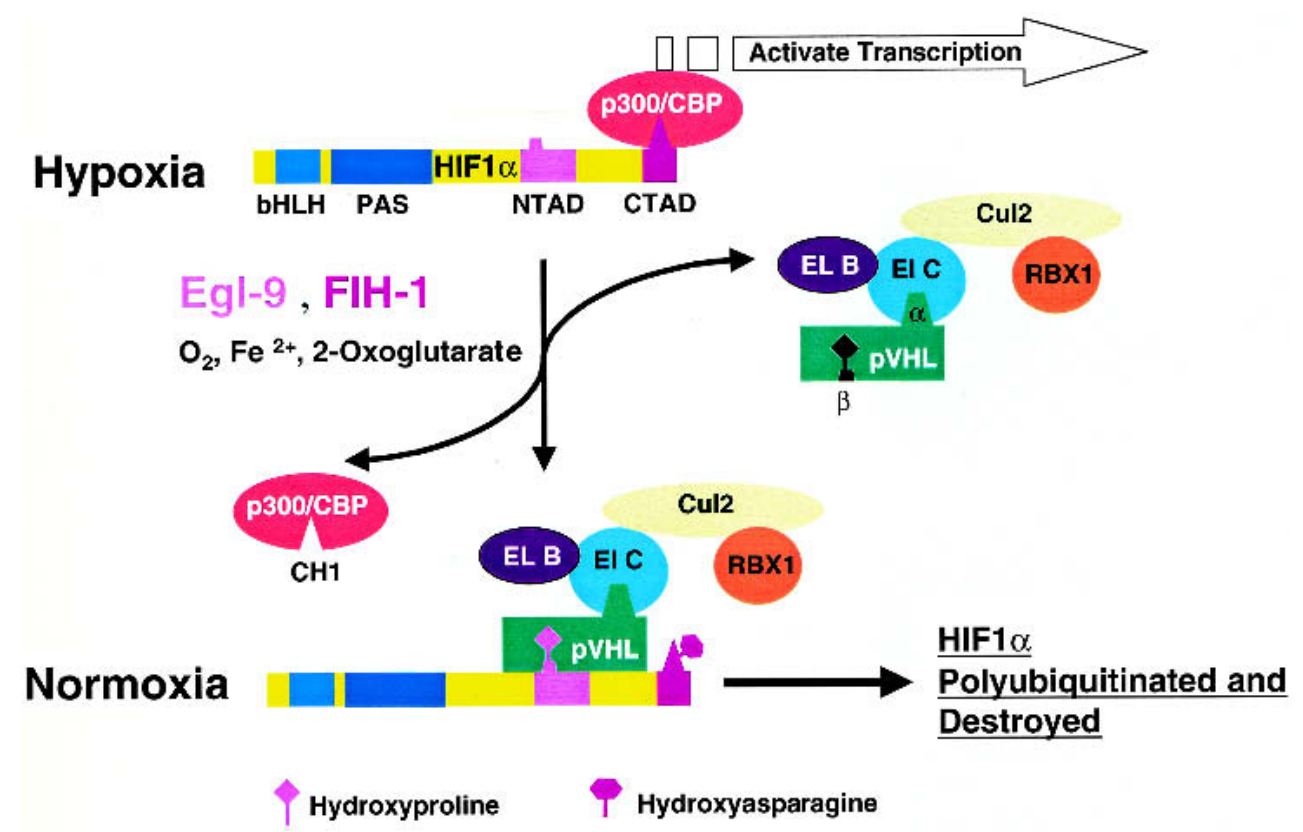

Figure 1. Hydroxylation of HIF-1 $\alpha$. Shown schematically is HIF-1 $\alpha$ with its basic helix-loop-helix (bHLH) domain, PAS domain, $\mathrm{N}$-terminal and C-terminal transactivation domains (NTAD and CTAD, respectively). In the absence of oxygen, the CTAD binds to p300 or CBP via their $\mathrm{CH} 1$ domains. In the presence of oxygen and the indicated cofactors, a conserved prolyl residue within the NTAD and a conserved asparaginyl residue in the CTAD are hydroxylated by an Egl-9 family member and FIH-1, respectively. For simplicity, a second, potential prolyl hydroxylation site in the vicinity of the NTAD is not shown. Asparaginyl hydroxylation leads to displacement of the p300 and CBP coactivators while prolyl hydroxylation causes pVHL to bind via its beta domain. The pVHL alpha domain, in turn, binds to elongin C (EL C), elongin B (EL B), Cul2, and Rbx1, which polyubiquitylate HIF-1 $\alpha$ and hence earmark it for proteasomal degradation. 
1996; Maxwell et al. 1999|. Furthermore, HIF variants that lack the pVHL-binding domain are able to activate hypoxia-inducible gene expression in the presence of oxygen (Elson et al. 2001; Kondo et al. 2002; Maranchie et al. 2002). One possibility, suggested by the work of Semenza and coworkers, is that pVHL loss compromises the function of FIH-1 (Mahon et al. 2001). Arguing against this idea is the recent finding that the effect of oxygen on CTAD function, at least as an isolated polypeptide, is pVHL-independent (Sang et al. 2002). A second possibility is that modulation of CTAD function by FIH-1 only affects a subset of HIF target genes and/or is restricted to certain tissues. In this regard, it is worth noting that a naturally occurring HIF- $1 \alpha$ splice variant that retains the NTAD, but lacks the CTAD, is still able to activate transcription (Gothie et al. 2000). One thing that is clear, however, is that HIF must escape pVHLdependent destruction if it is to undergo modification by $\mathrm{FIH}-1$. One can therefore argue a priori that FIH-1 hydroxylase activity will equal or exceed that of Egl-9 at any given oxygen concentration. In particular, FIH-1 may have evolved as a 'fine adjust' system over intermediate oxygen concentrations to complement the 'coarse adjust' provided by pVHL and Egl-9.

\section{Therapeutic opportunities}

Many of the major causes of morbidity and mortality in the developed world are diseases characterized by acute or chronic tissue hypoxia (ischemia). Among these diseases are myocardial infarction, stroke, and peripheral vascular disease. As suggested earlier, pharmacological blockade of HIF hydroxylation might augment the cellular response to hypoxia and thereby promote cell survival (Bruick and McKnight 2001a; Ivan et al. 2001). Studies of the collagen prolyl hydroxylases, which are required for collagen maturation, first established the feasibility of inhibiting this class of enzymes with small molecule iron antagonists or 2-oxoglutarate antagonists (Majamaa et al. 1984; Tschank et al. 1987; Gunzler et al. 1988; Baader et al. 1994; Franklin et al. 2001). A number of these compounds, including FG0041, also inhibit HIF hydroxylation by Egl-9 (Epstein et al. 2001; Jaakkola et al. 2001; Ivan et al. 2002). FG0041 was shown earlier to preserve myocardial function when administered $48 \mathrm{~h}$ after experimental myocardial infarction in rats (Nwogu et al. 2001). At the time, the rationale for these experiments was that FG0041 might inhibit collagen biosynthesis and thus prevent myocardial fibrosis, which is a late sequela of myocardial infarction. However, the fact that the beneficial effects of treatment were already measurable one week following infarction, as well as the absence of detectable fibrosis in the control animals, suggest that the salutary effects of FG0041 were instead linked to HIF stabilization (Nwogu et al. 2001; Ivan et al. 2002). This should become testable as compounds are developed that discriminate between the collagen and HIF prolyl hydroxylases.

One theoretical concern regarding the use of HIF agonists relates to the central role played by HIF in pVHL- defective tumors (Yang and Kaelin 2001). Inactivation of pVHL is linked to the development of a variety of tumors including blood vessel tumors of the central nervous system called hemangioblastomas, clear cell carcinomas of the kidney, and adrenal gland tumors called pheochromocytomas. Tumor-derived pVHL mutants are typically unable to polyubiquitinate HIF. In addition, production of HIF variants that escape pVHL control can override pVHL tumor suppressor activities in vitro and in vivo (Kondo et al. 2002; Maranchie et al. 2002). These findings suggest that down-regulation of HIF is necessary for tumor suppression by pVHL. Nonetheless, there is no evidence that deregulation of HIF is sufficient to cause tumor formation. Moreover, long term activation of HIF target genes in mouse skin and rabbit extremities with forms of HIF- $1 \alpha$ that are not recognized by pVHL induced the formation of functional blood vessels without evidence of tumors (Vincent et al. 2000; Elson et al. 2001). Nonetheless, it remains possible that chronic activation of HIF would promote tumor formation in certain tissues such as the brain and kidney. Even if this is true, it would not preclude short-term administration of HIF agonists for acute ischemic events.

\section{Other hydroxylated proteins?}

Previously, the best examples of enzymatically-mediated prolyl hydroxylation and asparaginyl hydroxylation involved secreted proteins that are modified in the endoplasmic reticulum. In particular, the role of prolyl hydroxylation in collagen biosynthesis has been known for years. Indeed, measurement of hydroxyproline was used in the past as a surrogate for monitoring collagen deposition in tissues. The EGF-like domains of a number of proteins are hydroxylated on asparagine in the endoplasmic reticulum by an enzyme that is overproduced in a variety of cancers (Przysiecki et al. 1987; Lavaissiere et al. 1996; Ince et al. 2000). The revelation that HIF, which resides in the nucleus, is regulated by prolyl hydroxylation and asparaginyl hydroxylation raises the question as to whether these modifications occur in other intracellular proteins. In contrast to many other posttranslational modifications, hydroxylation may have been easily overlooked in the past for a number of reasons. For example, hydroxylation barely alters the electophoretic mobility of proteins in polyacrylamide gels and does not alter their isoelectric points. In addition, nonenzymatic oxidation of amino acids such as methionine residues can occur during sample processing. The search can now begin in earnest for additional intracellular proteins that are regulated by hydroxylation. The histories following the discoveries of other posttranslational protein modifications suggest that additional hydroxylation targets will soon be discovered.

\section{References}

Aravind, L. and Koonin, E.V. 2001. The DNA-repair protein AlkB, EGL-9, and leprecan define new families of 2-oxoglu- 
tarate- and iron-dependent dioxygenases. Genome Biol. 2: research0007.1-0007.8.

Baader, E., Tschank, G., Baringhaus, K., Burghard, H., and Gunzler, V. 1994. Inhibition of prolyl 4-hydroxylase by oxalyl amino acid derivatives in vitro, in isolated microsomes and in embryonic chicken tissues. Biochem. J. 300: 525-530.

Bruick, R. and McKnight, S. 2001a. Building better vasculature. Genes \& Dev. 15: 2497-2502.

2001b. A conserved family of prolyl-4-hydroxylases that modify HIF. Science 294: 1337-1340.

Chandel, N., Maltepe, E., Goldwasser, E., Mathieu, C., Simon, M., and Schumacker, P. 1998. Mitochondrial reactive oxygen species trigger hypoxia-induced transcription. Proc. Nat1. Acad. Sci. 95: 11715-11720.

Dames, S., Martinez-Yamout, M., De Guzman, R., Dyson, H., and Wright, P. 2002. From the cover: Structural basis for Hif- $1 \alpha /$ CBP recognition in the cellular hypoxic response. Proc. Nat1. Acad. Sci. 99: 5271-5276.

Elson, D., Thurston, G., Huang, L., Ginzinger, D., McDonald, D., Johnson, R., and Arbeit, J. 2001. Induction of hypervascularity without leakage or inflammation in transgenic mice overexpressing hypoxia-inducible factor- $1 \alpha$. Genes \& Dev. 15: 2520-2532.

Epstein, A., Gleadle, J., McNeill, L., Hewitson, K., O'Rourke, J., Mole, D., Mukherii, M., Metzen, E., Wilson, M., Dhanda, A., et al. 2001. C. elegans EGL-9 and mammalian homologs define a family of dioxygenases that regulate HIF by prolyl hydroxylation. Cell 107: 43-54.

Franklin, T., Morris, W., Edwards, P., Large, M., and Stephenson, R. 2001. Inhibition of prolyl 4-hydroxylase in vitro and in vivo by members of a novel series of phenanthrolinones. Biochem. J. 353: 333-338.

Freedman, S., Sun, Z., Poy, F., Kung, A., Livingston, D., Wagner, G., and Eck, M. 2002. Structural basis for recruitment of CBP/p300 by hypoxia-inducible factor-1 $\alpha$. Proc. Nat1. Acad. Sci. 99: 5367-5372.

Gothie, E., Richard, D., Berra, E., Pages, G., and Pouyssegur, J. 2000. Identification of alternative spliced variants of human hypoxia-inducible factor-1 $\alpha$. J. Biol. Chem. 275: 6922-6927.

Gunzler, V., Hanauske-Abel, H., Myllyla, R., Kaska, D., Hanauske, A., and Kivirikko, K. 1988. Syncatalytic inactivation of prolyl 4-hydroxylase by anthracyclines. Biochem $I$. 251: 365-372.

Iliopoulos, O., Jiang, C., Levy, A.P., Kaelin, W.G., and Goldberg, M.A. 1996. Negative regulation of hypoxia-inducible genes by the von Hippel-Lindau protein. Proc. Natl. Acad. Sci. 93: 10595-10599.

Ince, N., de la Monte, S., and Wands, J. 2000. Overexpression of human aspartyl (asparaginyl) $\beta$-hydroxylase is associated with malignant transformation. Cancer Res. 60: 1261-1266.

Ivan, M., Kondo, K., Yang, H., Kim, W., Valiando, J., Ohh, M., Salic, A., Asara, J., Lane, W., and Kaelin, W.G. 2001. HIFo targeted for VHL-mediated destruction by proline hydroxylation: Implications for $\mathrm{O}_{2}$ sensing. Science 292: 464-468.

Ivan, M., Haberberger, T., Gervasi, D., Michelson, K., Gunzler, V., Kondo, K., Yang, H., Sorokina, I., Conaway, R., Conaway, J., et al. 2002. Biochemical purification and pharmacological inhibition of a mammalian HIF prolyl hydroxylase. Proc. Natl. Acad. Sci. (in press).

Jaakkola, P., Mole, D., Tian, Y., Wilson, M., Gielbert, J., Gaskell, S., Kriegsheim, A., Hebestreit, H., Mukherji, M. Schofield, C., et al. 2001. Targeting of HIF- $\alpha$ to the von Hippel-Lindau ubiquitylation complex by $\mathrm{O}_{2}$-regulated prolyl hydroxylation. Science 292: 468-472.

Kivirikko, K.I. and Myllyharju, J. 1998. Prolyl 4-hydroxylases and their protein disulfide isomerase subunit. Matrix Biol. 16: $357-368$

Kondo, K., Klco, J., Nakamura, E., Lechpammer, M., and Kaelin, W.G. 2002. Inhibition of HIF is necessary for tumor suppression by the von Hippel-Lindau protein. Cancer Cell 1: 237246.

Lando, D., Peet, D.J., Gorman, J.J., Whelan, D.A., Whitelaw, M.L., and Bruick, R. 2002a. FIH-1 is a an asparaginyl hydroxylase that regulates the transcriptional activity of hypoxia inducible factor. Genes \& Dev. 16: 1466-1471

Lando, D., Peet, D.J., Whelan, D.A., Gorman, J.J., and Whitelaw, M.L. 2002b. Asparagine hydroxylation of the HIF transactivation domain: A hypoxic switch. Science 295: 858-861.

Lavaissiere, L., Jia, S., Nishiyama, M., de la Monte, S., Stern, A., Wands, J., and Friedman, P. 1996. Overexpression of human aspartyl(asparaginyl) $\beta$-hydroxylase in hepatocellular carcinoma and cholangiocarcinoma. J. Clin. Invest. 98: 1313-1323.

Mahon, P., Hirota, K., and Semenza, G. 2001. FIH-1: A novel protein that interacts with HIF-1 $\alpha$ and VHL to mediate repression of HIF-1 transcriptional activity. Genes \& Dev. 15: $2675-2686$.

Majamaa, K., Hanauske-Abel, H., Gunzler, V., and Kivirikko, K. 1984. The 2-oxoglutarate binding site of prolyl 4-hydroxylase. Identification of distinct subsites and evidence for 2-oxoglutaratedecarboxylation in a ligand reaction at the enzyme-bound ferrous ion. Eur. J. Biochem. 138: 239-245.

Maranchie, J.K., Vasselli, J.R., Riss, J., Bonifacino, J.S., Linehan, W.M., and Klausner, R.D. 2002. The contribution of VHL substrate binding and HIF- $1 \alpha$ to the phenotype of VHL loss in renal cell carcinoma. Cancer Cell 1: 247-255.

Masson, N., Willam, C., Maxwell, P., Pugh, C., and Ratcliffe, P. 2001. Independent function of two destruction domains in hypoxia-inducible factor- $\alpha$ chains activated by prolyl hydroylation. EMBO J. 20: 5197-5206.

Maxwell, P., Weisner, M., Chang, G.-W., Clifford, S., Vaux, E., Pugh, C., Maher, E., and Ratcliffe, P. 1999. The von HippelLindau gene product is necessary for oxgyen-dependent proteolysis of hypoxia-inducible factor $\alpha$ subunits. Nature 399: 271-275.

Min, J.-H., Yang, H., Kaelin, W., and Pavletich, N. 2002. Structure of a pVHL-HIF-1 $\alpha$ complex: Hydroxyproline recognition in intracellular signaling. Science (in press).

Nwogu, J.I., Geenen, D., Bean, M., Brenner, M.B., Huang, X., and Buttrick, P.M. 2001. Inhibition of collagen synthesis with prolyl 4-hydroxylase inhibitor improves left ventricular function and alters the pattern of left ventricular dilation after myocardial infarction. Circulation 104: 2216-2221.

Przysiecki, C., Staggers, J., Ramjit, H., Musson, D., Stern, A., Bennett, C., and Friedman, P. 1987. Occurrence of $\beta$-hydroxylated asparagine residues in non-vitamin K-dependent proteins containing epidermal growth factor-like domains. Proc. Natl. Acad. Sci. 84: 7856-7860.

Sang, N., Fang, J., Srinivas, V., Leshchinsky, I., and Caro, J. 2002 Carboxyl-terminal transactivation activity of hypoxia-inducible factor $1 \alpha$ is governed by a von Hippel-Lindau protein-independent, hydroxylation-regulated association with p300/CBP. Mol. Cell Biol. 22: 2984-2992.

Schofield, C.J. and Zhang, Z. 1999. Structural and mechanistic studies on 2-oxoglutarate-dependent oxygenases and related enzymes. Curr. Opin. Struct. Biol. 9: 722-731.

Semenza, G. 1999. Perspectives on oxygen sensing. Cell 98: $281-284$.

2001. HIF- $1, \mathrm{O}_{2}$ and the 3 PHDs: How animal cells signal hypoxia to the nucleus. Cell 107: 1-3. 
Srinivas, V., Leshchinsky, I., Sang, N., King, M., Minchenko, A., and Caro, J. 2001. Oxygen sensing and HIF-1 activation does not require an active mitochondrial respiratory chain electron-transfer pathway. J. Biol. Chem. 276: 21995-21998.

Taylor, M.S. 2001. Characterization and comparative analysis of the EGLN gene family. Gene 275: 125-132.

Tschank, G., Raghunath, M., Gunzler, V., and Hanauske-Abel, H. 1987. Pyridinedicarboxylates, the first mechanism-derived inhibitors for prolyl 4-hydroxylase, selectively suppress cellular hydroxyprolyl biosynthesis. Decrease in interstitial collagen and Clq secretion in cell culture. Biochem. J. 248: 625-633.

Vaux, E., Metzen, E., Yeates, K., and Ratcliffe, P. 2001. Regulation of hypoxia-inducible factor is preserved in the absence of a functioning mitochondrial respiratory chain. Blood 98: 296-302.

Vincent, K., Shyu, K., Luo, Y., Magner, M., Tio, R., Jiang, C., Goldberg, M., Akita, G., Gregory, R., and Isner, J. 2000. Angiogenesis is induced in a rabbit model of hindlimb ischemia by naked DNA encoding an HIF-1 $\alpha / \mathrm{VP} 16$ hybrid transcription factor. Circulation 102: 2255-2261.

Yang, H. and Kaelin, W.G. 2001. Molecular pathogenesis of the von Hippel-Lindau hereditary cancer syndrome: implications for oxygen sensing. Cell Growth Differ. 12: 447-455.

Yu, F., White, S., Zhao, Q., and Lee, F. 2001. HIF-1 $\alpha$ binding to VHL is regulated by stimulus-sensitive proline hydroxylation. Proc. Natl. Acad. Sci. 98: 9630-9635. 


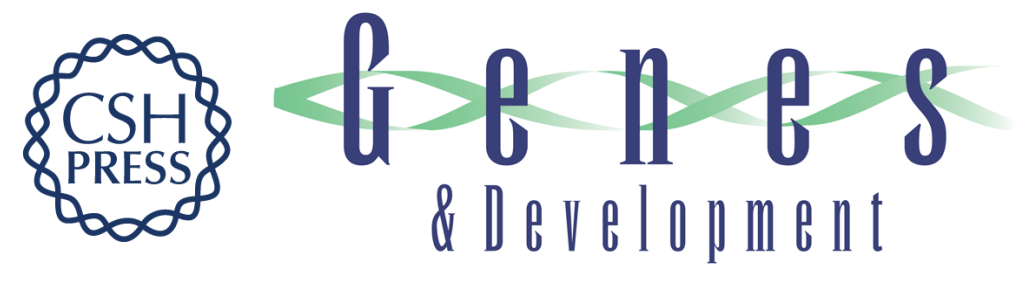

\section{How oxygen makes its presence felt}

William G. Kaelin, Jr.

Genes Dev. 2002, 16:

Access the most recent version at doi:10.1101/gad.1003602

References This article cites 38 articles, 24 of which can be accessed free at: http://genesdev.cshlp.org/content/16/12/1441.full.html\#ref-list-1

License

Email Alerting Receive free email alerts when new articles cite this article - sign up in the box at the top Service right corner of the article or click here.

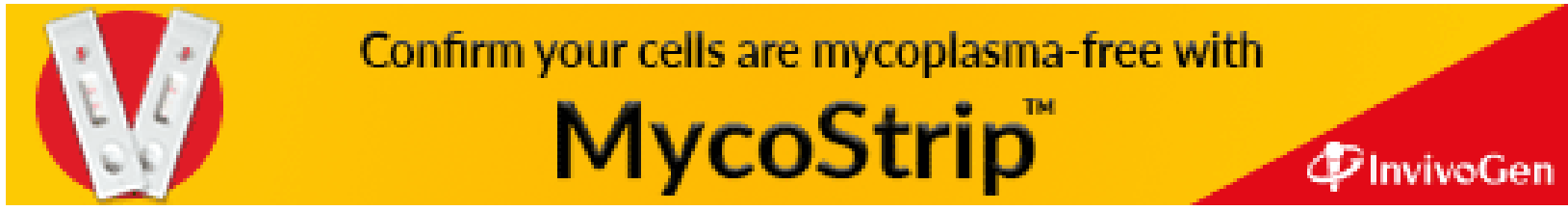

